\title{
The Role of Prison Service in Reducing Re-offence: Challenges of (Re) Integration in Illu Abba Bor and Bunno Bedelle Zones Prisons, Ethiopia
}

\author{
Chali Etefa Taye \\ Policy researcher, FDRE policy Studies Institute
}

\begin{abstract}
This study is aimed at examining factors of (re)-offending, the role of prison administration and its challenges in reducing (re)-offending by (re)-integration mechanism. The approach employed qualitative and its design was descriptive case study. The data were collected through semi-structured interview, focus group discussion and observation. The data collected was categorized, organized in theme and analysed by thematic analysis techniques. And then, the study find out that there are three interrelated phases as far as (re)-integration is concerned: programs that take place during time in prison, which aim to prepare offenders for their eventual release; programs that take place during offenders' release period, which seek to connect ex-offenders with the various services they may require; and long-term programs that take place as ex-offenders permanently (re)integrate into their communities, which attempt to provide offenders with support and supervision. To perform it, there were responsible departments in prison administration that play a role in each phases by arranging Substance Abuse Treatment Programmes, Facilitating Behavioural Change of Offenders, providing Education, Life Skills and Vocational Training and setting up Follow Up Mechanisms and Linkage. However, limited economic and human resource/Capital, weak linkage of the correctional centres with the community and other stakeholder, public perception of discharged prisoners in the community and principle-practice disparity on the role of correctional centres prevented correctional centres from properly executing its responsibilities. The study concludes that rehabilitation of the offender and the support of the victim, by way of a multidisciplinary approach and the presentation of a variety of programmes, should always be the main aim of imprisonment in order to re-integrate the offender with society and the family so that they can once again function as a proper unit. To this end, the study suggested that mechanisms should be devised to participate and mobilize all sectors towards the same aim of reducing reoffending.
\end{abstract}

Keywords: prison, (Re)-offense, Offenders, (Re)-integration, crime

DOI: $10.7176 / \mathrm{PPAR} / 10-2-01$

Publication date: February $29^{\text {th }} 2020$

\section{Introduction}

From the world experience, the offenders punished to minimize the crime. The form and purpose of punishment might be different from one to another. For example; punishment may take the form of imprisonment, fine, probation, corporal punishment, capital punishment, community service, conditional or unconditional discharge. Its purpose is ensuring and preserving order, peace, and security of the state and its in habitats for the public goods (Girma, 2013)

However, detailed history of prison in Ethiopia is incomplete and limited, it has been served as correction centre (Factbook, 2004). It serve to correct criminal behaviour. A crime is an act which is prohibited and made punishment by law. An act consists of the commission of what prohibited or the omission of what is prescribed by law (The criminal code of Ethiopia proclamation No.414/2005, 2005). Criminal law is among the guardian of the society and its inhabitants. It protects the society by encouraging the performance of desirable acts and discouraging the commission of acts that deemed socially undesirable. As a point of departure, criminal law protects the society/preserve public good whereas civil law is meant to protect persons/preserve individual good and their properties (Girma, 2013). As Dejene said punishment normally refers to measures taken by the government against criminals as the consequences of their criminal activities so as to affect, inter alia, their property, liberty and times, lives. In the contemporary time, sending inmates to prison is the most practiced forms of punishment throughout the world, though different states may pursue their own distinct aims and philosophy in dealing with prisoners (Lauren E. Glanze and Seri Palla, 2006).

There are several theories about the Prison authorities to protect the community from crime offenders. some of them are: retribution, deterrence, rehabilitation and incapacitation of offenders (Girma, 2013). For the concern of this study, the emphasis would be on Rehabilitation.

Rehabilitation is also known as reformation, supports the claim that sentence should be designed to provide treatment for conditions in offender's attitude, personality or general personal history that have led him to the commission of a crime. It is about how to reform or cure the offender from problem that might have led him/her to the commission of crime. This is forward-looking theory of punishment as it aims at rehabilitating criminals 
so as to enable them to lead normal (criminal-free) life after completely serving their sentences. It expected to minimize the likelihood of ex-prisoners reoffending after they released. One strategy for reducing the risk of recidivism is the provision of treatment, services and support to prisoners during their incarceration and after their release. It is recognized that prisoners are confronted by a arrange of social, economic and personal challenges that can be barriers to a criminal free life style (Baldry, 2003)

The Universal Declaration of Human Rights, The International Covenant on Economic, Social and Cultural Rights, and The United Nations Basic Principles for the Treatment of prisoners facilitate the route of rehabilitation to ensure that inmates are treated with care and dignity. Ethiopia is among countries that subscribe to these international conventions. The Bill of Rights enshrined in chapter three of the Constitution of the Republic of Ethiopia of 1995 with reference to the detention system defines how the justice system should operate, which emulates international statutory measures with regard to the treatment of prisoners.

Moreover, the federal prison Commission was established pursuant to Proclamation No. 365/2003, to implement judicial decisions and to undertake the functions of the custody, reformation and rehabilitation of prisoners as part of the contribution to crime prevention. For further lightening of the Ethiopian legal concern about detainees:

\subsection{The 1931 Constitution}

In 1931 Ethiopia adopted the first written constitution. The constitution, for the first time in the history of Ethiopian Human Rights, came up with some human rights provisions. The article which has relevance to detained persons prohibits arbitrary arrest, sentence and imprisonment of persons: - No Ethiopian subject may be arrested, sentenced, or imprisoned except in pursuance of the law. This provision, however, does not have clear provision on treatment of detained persons.

\section{Proclamation No. 45/1944, Relating To Prisons}

Ethiopia has a brief history of legal framework concerning the treatment of prisoners, though history of prisons in Ethiopia is traced back long before 20th century. Proclamation No. 45 of 1944 entitled a proclamation Relating to prisons pioneered in bridging the vacuum in this regard. According to article 8 of the prison proclamation, prisoners serving sentences are under obligation to participate in some work in the prison and this type of work is considered to be "an essential element" in the sentence. The type of work should also be suitable to the prisoners' ability and - shall be of such nature as to reform and educate the prisoner and to be conductive to his rehabilitation. If the work the prisoner does and his conduct are satisfactory, he is entitled to receive compensation for the work he does. The mode and amount of payment was supposed to be governed by prison regulations.

\section{The 1957 Criminal Code}

The 1957 criminal code had described the manner of prisons administration and treatment of prisoners. The code, accordingly served to supplement the proclamation on the administration of prisons. In line to our objectives some of the provisions of the code capture our attention in terms of their relevance for the topic under investigation. Among others, prisoners, who are a danger to others, prisoners of bad character and recidivists sentenced to rigorous imprisonment or interment shall be kept separate from prisoners under the age of 18 years or from prisoners who are serving a sentence of simple imprisonment for the first time. Moreover, prisoners on remand or prisoners detained for civil debts shall be kept separate from prisoners serving sentences.

\section{The 1995 FDRE Constitution}

The constitution provides a long list of fundamental rights and freedoms under chapter three. The chapter is divided into two parts as: Human Rights' and Democratic Rights'. Everyone, without discrimination on different backgrounds, is entitled to the rights entrenched in the constitution. Detained persons as human beings, therefore, are also entitled for these constitutional rights, except those limited explicitly as natural consequence of deprivation of liberty. For instance, the rights to life can be limited as a punishment for a serious criminal Offence determined by law: No person may be deprived of his life except as a punishment for a serious criminal offence determined by law. Art 14 grants the rights to liberty and this rights is taken by law obviously as punishment for crime. The said article at the same time, however, prohibits arbitrary arrest and detention without charge or conviction. Article 18 of the FDRE constitution is a direct reflection of art 5 of the UDHR and article 7 of the ICCPR stating -Everyone has the rights to protection against cruel, inhuman or degrading treatment or punishment. It specifically prohibits forced or compulsory labor' and exceptionally detained persons are required to perform forced or compulsory labor.

The constitution on The Rights of Persons Held in Custody and Convicted Prisoners' reaffirmed that detained persons are entitled to the rights guaranteed by the constitution, all persons held in custody and persons imprisoned upon conviction and sentencing have the rights to treatments respecting their human dignity. The 
provision continues: All persons shall have the opportunity to communicate with, and to be visited by, their spouses or partners, close relatives, friends, religious councilors, medical doctors and their legal counsel.

The EFDR constitution has adopted the monist approach on incorporation of international law. Art 9(4) of the constitution stipulates that -All international agreements ratified by Ethiopia are an integral part of the law of the land. Hence, International instruments that are ratified by Ethiopia are subject to enforcement before domestic courts without the need for further act for domestication. Accordingly, international human rights instruments in general and those exclusively dedicated to detained persons rights can be invoked by detainees so long as ratified by Ethiopia.

\section{Federal Prisons Commission Establishment Proclamation}

Federal Prisons Commission Establishment Proclamation, adopted by the house of people's representatives to give effect to the principles envisaged by the constitution regarding persons in custody, is the next important instrument which deals with detainees rights. The preamble of the proclamation stipulates that reformation and rehabilitation are the objectives of punishment. Art 5 of the proclamation also states that the objective of the commission is reformation and rehabilitation:

The objectives of the Commission shall be to admit and ward prisoners, and provide them with reformative and rehabilitative service in order to enable them make attitudinal and behavioral changes, and become law abiding, peaceful and productive citizens.

Art 6 of the same proclamation on - Powers and Duties of the Commission provides that the commission shall maintain prisoners' health care; and provide prisoners with free medical treatment, food and shelter. It will undertake and encourage tasks, services and activities necessary for the physical and mental well-being of prisoners. To this end, the proclamation stipulates enactment of regulation and directives by relevant authorities. The duty of the commission also includes, inter alia, providing prisoners with academic education, vocational training, and social work services and counseling services to facilitate their post-release rehabilitation.

The proclamation provides that prisoners shall be treated with due regard to their human dignity. It also suggests that remand and civil prisoners shall be presumed innocent and treated differently from convicted prisoners. It prohibits adverse discrimination on grounds of gender, religion, political opinion, nation, nationality, of social origin. The proclamation makes it clear that female detainees shall be provided with separate premises while segregation on the basis of age, offences and similar factors is subject to the extent that circumstances allow. 'Prison premises and compounds shall not be hazardous to health; and they shall have fresh air and sufficient lights. It allows variation among accommodations based on degree of willingness to reform and repentance. There shall be provision of food free of charge which is sufficient and of nutritional value.

\section{The Revised Criminal Code (2004)}

The significance of the existing criminal code, which repealed the 1957 penal code, of Ethiopia will not be overlooked when we deal with a law that governs prisoner's rights in Ethiopia. Article 1 of the criminal code on object and purpose' of the criminal law of Ethiopia stipulates that the purpose of the criminal code is ensuring order, peace and security. To this end, the aim of the law is mainly prevention of crime by giving due notice on the types of prohibited acts and the amount and nature of punishment that the violation of them entails. The purpose of punishments passed against those who failed to adhere to the law is not retribution. It is to deter others not to involve with the same act and at the same time it endeavors to make reformation of the criminals through different measures. The reformation and rehabilitation objective of the law is best provided, specifically regarding prisoners, under its preface. The preface upholds article 1of the code:

The fact that wrongdoers, 'instead of being made to suffer while in prison, take vocational training and participate in academic education, which would benefit them upon their release, reaffirms the great concern envisaged by the Criminal Code about the reform of criminals.

\section{Regulations No.138/ 2007: 'Treatment of Federal Prisoners'}

In 2007 the Council of Ministers enacted regulations entitled the "Treatment of Federal Prisoners Council of Ministers Regulations No.138/ 2007". The regulation under article three describes the basic principle in dealing with prisoners and prison administration. First, it prohibits any 'discrimination on grounds of gender, language religion, political opinion, nation! nationality, social status or citizenship; second, respect to their human dignity unless restricted by the penalties imposed on them; third, ensuring that the executions of penalties are educative and rehabilitative.

As the basic principle of the treatment of prisoners' stated that punishments at prison service expected to be educative and rehabilitative. This provision also emphasized under article 23 which states that:

Prisoners shall be provided with the opportunity to attend academic and different vocational training classes; provided, however, that priority shall be given to illiterate 
prisoners.

The regulation goes to say that 'Particular attention shall be paid to give educational opportunities to female and juvenile prisoners.' In line to this article 24 of the regulation impose additional duties...the prison shall make the necessary arrangements to allow prisoners to participate in different rehabilitation and recreational activities. Furthermore, as per article 25 of the regulation, professional counseling service shall be provided to prisonersduring their stay in prison to bring about behavioral change so that they can become law abiding and productive citizens after their release.

At the times individuals may commit crimes due to the problems external or internal they are suffering from. Thus, since they may get rid of their problems through punishment, the criminal code stipulates the use of reformative penalties. For example, individuals who steal because of poverty may be given vocational trainings in jails so that they will be able to use their vocations after they are released. The third means to be employed to hit the target of criminal law is measures. They can be used to prevent the commission of further crimes and this can happen where there is an indication to the effect that a crime will be committed Even, the process of rehabilitation often considered of severe beatings, exhausting work and calisthenics, and political indoctrination. In Ethiopia the term prison is as old as the formation of the so called Ethiopian state. It is called as "Carchalle", "Mana Hidha" and "weyinbet" in different part of the society. Prisons are often described as places where bad people go to get worse (Munting, 2005).

From the above literature background, this examines issues linked to the provision of services provided to prisoners during their incarceration and after their release.

\section{Statement of the Problem}

During the period of incarceration the prison should allow the offender an opportunity to work at reforming lives, showing them that crime does not pay, teaching them a marketable skill, giving them an education, all with one end in mind - to reduce the chance of an offender reoffending after release (Stern, 2007). One less recidivist means one less crime, which means one less victim of crime and one less harm caused, hence a safer environment for all (Baldry, 2003); (Nsanze, n.d). Some study also shows that unpreparedness of families and community may be worrisome than being in prison leaving the ex-convict with no choice, but to re-offend and be reconvicted and a recidivist (Boipelo Milly Raboloko and Kgosictsile Maripe, 2019). Others Study results confirmed that provision of treatments, services and support to prisoners during their imprisonment and after release, reduced the likelihood of ex-prisoners reoffending after they released (Baldry, 2003). From the above, this study aim to assess the prison services in the process of reintegration and challenges to implement the reintegration program.

\section{Objective of the Study \\ General Objective}

The overall objective of this study was assess the role of prison service in reducing re-offending: challenges of (re)-integration in the case of Ilu Abba Bor and Buno Bedele Zones.

\section{Specific Objectives}

To Identify the general overview of offence and reoffending in the study area.

To explore the causal factors to ex-prisoners to reoffend.

To assess the role of correctional institutions and other stakeholders in preparing offenders for release, thereby aiding the reintegration process.

\section{Research Questions}

The research has attempted to address the following research questions:

$\checkmark \quad$ Why do some offenders return to prison repeatedly while others are able to move on and desist from crime?

$\checkmark$ Can prisons play a more effective role in preparing offenders for release, thereby aiding the reintegration process?

$\checkmark$ Do the community and other stakeholders have participated in making the transition from prison into the community more successful?

$\checkmark$ What are the challenges incarcerated individuals experience when they reenter society after incarceration?

$\checkmark$ What can be done to 'bridge the gap' making the transition from prison into the community more successful?. 


\section{Methodology of the Study \\ Study design}

This study was qualitative approach and designed as descriptive case study. Qualitative approach since the study focuses on the description of subjective perspectives, processes and contextual meaning. It was also focuses on specific institution and limited to the prisons under study.

In order to relate the finding of this study with the existing literatures, secondary sources have also used. Moreover, documents and records of correctional services from each zone have been used as additional sources of data. Hence, social norms, the perception of the research participants and the attitude of the people gauged qualitatively by probing the data collected through interviews, key informants, document analysis and observation.

\section{Participants of the Study}

Participants of the study includes prisoners who offended more than once, correctional officials, police and court officers, kebele personnel who has worked in adjudicating crime, community elders and families of imprisoned person in the area. Elders were selected considering their roles in the community. Largely we depended on correctional officers, Police and court offices in selecting local officials for in-depth interview. The key informants were selected considering the previous or the current position and experiences of the informants in relation to prison service.

\section{Sampling Techniques and Procedures}

This study would employed both probability and non-probability sampling procedures. Probability sampling have been used in selecting weredas from each zones. Using probability sampling three weredas from Ilu Abba Bor and two from Buno Bedelle zone have been selected. Non probability sampling was used to select participants. Purposive sampling was employed to select the participants in the prison/prisoners and correctional officers. Purposive-sampling technique in which respondents are selected on the basis of certain predefined purposes employed as a tool to select the informants. The rationale is, the researcher would found and discern individuals with knowledge and experience about the study. The size of the participants determined by the levels of data saturations. To this end, the selection of informants and the interview were done by the help of research assistants, from each woreda and one coordinator at zonal level. In this stage of selecting the representatives, the researcher was vastly cautious in order to stay away from unobtrusive prejudice.

\section{Instruments of Data Collection In-depth and Key Informants Interview}

In-depth interview had been conducted. It was administered to 50 prisoners of which 20 was female and 30 male, 8 line managers of Prison administration, 20 ex-prisoners and 80 community members purposively. The interviews had been administered focused on those their perception on prison services, preparation for future life and challenges to them. Accordingly, the data on views, feelings, emotions and experiences of respondents collected.

\section{Key Informants Interview}

In order to triangulate the data obtained from in-depth interviews. For this purpose, ten(10) informants(with deep experiences and information about re-offence) selected using purposive sampling. Among these, two from each department of correctional services and a total of six from Woredas justice sectors.

\section{Focus group Discussion}

Focus group discussion was held with re-offenders in prison classifying in to 4 groups. each group has 8 members. This was done to obtain detail information for they back to prison after they had released.

\section{Document Analysis}

In order to find the level of reoffending in the study area documents which are relevant to the issue under study were analyzed. In this regards, documents and records in the correctional services have been given due attention. The information obtained from document analysis were employed to cross check the data obtained through indepth and key informants interviews. Furthermore, the researchers have examined the available documents on the issue such as policy manuals and strategic documents and international research on reducing reoffending, performance reports, training manuals and action plans.

\section{Methods of Data Analysis}

The study was employed thematic descriptive data analysis method. The data obtained from in-depth, key informants interview focus Group discussion, document analysis and field notes (observation) have been 
systematically formulated and summarized to point out the needed issues. This task was carried out by applying pertinent approach to qualitative method.

In the meantime, triangulation of data have been predominantly used to compare and contrast the data obtained from different sources descriptively. As part of drawing inferences and establishing relationships within the collected data, the contents, which have similarities, were organized into categories and subcategories. This was followed by further clustering of different contents and then, the researchers have coined the most descriptive topics that capture the content or the essence of each theme.

\section{Findings}

\subsection{The level of Re-Offending}

The researchers organized and presented the frequency of re-offending in Both Illu Abba Bor and Bunno Bedelle as follows:

The data revealed that, the frequency of committing theft was significantly higher than the rest offences. A data pertaining to reoffending shows the same reality as most of ex-prisoners who have been convicted as a result of their engagement in some kind of theft come back to prison at some point of their release. From a total of 511 convicts due to their engagement in some kind of theft $146(28.57 \%)$ of them visited the correctional centres more than once. Next to theft, physical harm stands second regarding the frequency to which the offence is committed in the area. From the total 338 prisoners who visited the two correctional centres by inflicting certain physical harm/damage $58(11 \%)$ of them were previously attended the prison centre at least once. The data found that from the total of 1284 inmates who visited the correctional centres as a result of theft, murder, physical harm, deforestation and rape $241(20 \%)$ of them are reconvicted at least for the second time or more. Therefore, the effort to reduce reoffending and break the cycle of crime needs to focus on this fact.

The data both from Ilu Aba Bora \& Buno Bedelle suggests that offenders whose current conviction was either burglary or theft were twice as likely to be reoffend compared to prisoners who had committed other types of offences. According to one of the Commander, who is a chief officer in correctional center, offenders who commit relatively low-level crimes but in high volumes are more likely to be reconvicted, and these offenders are more likely to get short custodial sentences. In contrast, longer custodial sentences are usually given to offenders who commit more serious crimes, but these types of crimes are much more rare, and the people responsible for them are less likely to be reconvicted.

\subsection{Factors Which Influence Reoffending}

\subsubsection{Education}

According to the data from prisoners both in Ilu Abba Bor and Bunno Bedelle prison center most prisoners have had no, a limited, or a severely disrupted education. As part of data collection, we interviewed 44 prisoners from Ilu Abba Bor and 26 from Bunno Bedelle correctional centres. All of them were men and visited the correctional centres more than once. At this point, we can analyze the educational back ground of our informants to indicate the link between educational background and the level of reoffending.

Table 4: Educational background research participants/ reconvicted inmates

\begin{tabular}{|l|l|l|l|l|l|}
\hline \multirow{2}{*}{ S.N } & \multirow{2}{*}{ Educational level } & \multicolumn{2}{|c|}{ Prison centre } & Total & \multirow{2}{*}{ Percent (\%) } \\
\cline { 3 - 4 } & & Ilu Abba Bor & Bunno Bedelle & & \\
\hline 1 & Illiterate & 14 & 6 & 20 & 28.57 \\
\hline 2 & $1-4$ & 16 & 8 & 24 & 34.28 \\
\hline 3 & $5-8$ & 8 & 6 & 14 & 20 \\
\hline 4 & $9-10$ & 4 & 5 & 9 & 12.85 \\
\hline 5 & Technical \& vocational & 2 & 1 & 3 & 4.28 \\
\hline & Total & 44 & 26 & 70 & 100 \\
\hline
\end{tabular}

\section{Substance Abuse}

Studies have shown that rates of substance abuse amongst prisoners and ex-prisoners are substantially higher than for the general population. According to some of the informants, both in Ilu Abba Bor and Bunno Bedelle drinking of alcohol is particularly associated with violence. Although they have admitted that excessive consumption of alcohol inflict some kind of violent behavior, they are not honest enough to share their personal experience in this regard. However, according to our informants from the prison service staff, the behavior exhibited by most inmate during their arrival at the prison centre and also throughout their stay witnessed their consumption of some kind of drug or alcohol.

Problematic alcohol consumption is associated with crime, particularly heavy or binge drinking and violent crime. However, the links between alcohol, crime and reoffending are complex: other mediating factors, for example personality disorder, childhood experiences of violence and social/cultural norms, are likely to play a 
role in the relationship between alcohol misuse and violent crime. There is a link between alcohol misuse and reoffending: for example, prisoners who had drunk alcohol every day shortly prior to custody were more likely to be reconvicted within a year following release than those who had not.

The habit of chewing khat is also wide-spreading in the area from time to time. Almost above half of the youth in Mettu town chew khat. The highest percentage of the prison population also constitute the youth. Chewing khat may contribute to the crime in general and reoffending in particular in to two ways: first, just like other drug khat activates the mind and take them out of the reality, there by exposing the youth to emotional and imaginary activities which is against recognized norms of the society. Second, once they are addicted they use any means possible to get it. The youth who engaged in chewing khat are mostly unemployed. They couldn't have permanent income to cover the cost of khat. Therefore, they can engage in different illegal activities including theft. As indicated above, the finding suggest that in the crime as well as in the degree of reoffending theft stand first. In general, in the study area it has been estimated that approximately 70 per cent of prisoners have a substance abuse problem and those individuals have never received treatment during their stay in prison service.

Pro Crime Attitudes and Self-Indulgence

Attitudes involve the perception and misperception of prisoners towards crime. Culture affects our perception profoundly. According to our informants, those crimes related to revenge are mostly attributed to culture. The culture of revenge plays a great role in sustaining the cycle of crime and reoffending. Most prisoners during their re-entry may face problems of resettlement. The main reason for this, according to one of our informant, first the offender may find some of his family or property being affected by the so called victim or his/her family. Second, when the offender comes back to the community the families of the so called victim intimidate and harass $\mathrm{him} / \mathrm{her}$. At this time, the offender forced to show violent behavior and re-offend. Furthermore, prisoners often come from socially excluded groups in society that may regard crime as a way of life or an easy way of making money, and, in fact, may regard prison as an inevitable part of their lifestyle. We identify such an attitude during our stay with the prisoner both in Ilu Aba Bor and Buno Bedelle Zones. One of the offenders in Ilu Aba Bor correctional centere testified that:

We prefer to stay here. Life is more easy in prison centre than the outside world. Here, in the prison centre, we find food to eat without any ups and downs. They provide us beds which is much better than ours. So, why we suffer the hardship of life outside?

Thus, for some offenders, prison may be the only place they have support and when they leave prison they lose that support. Conversely, most of offenders interviewed in Mettu and Bedelle prison center felt they had more support in the community and described prison as a terrible place, with minimal support.

\section{Institutionalization and Life-skills}

Many prisoners have had disadvantaged family backgrounds, which were exacerbated by early institutionalization, and limited opportunities to develop the life-skills needed for them to function in society. Limited problem solving skills and a tendency to act impulsively are common to many offenders and are likely to inhibit successful resettlement. A significant number of offenders both in Ilu Aba Bor and Bunno Bedelle prison services have been identified as having poor problem solving skills and an equally high percentage are considered to be impulsive. This is clearly self evident as we have discussed the reason of their arrest/re-arrest. Furthermore, imprisonment may tend to delay maturation, damage social ties and reinforce a negative identity.

\section{Problems of Housing}

According to our informants, a significant number of prisoner loses their accommodation while in prison. This means that when released from prison many offenders find themselves homeless. This is caused mainly due to two reasons: first if the crime committed by the offender is a serious one like killing, then the families of the victims take measures of revenge on the relatives and the properties of the offender including firing his house. For instance, three of our interviewee in Mettu prison centre confirmed this by stating the fact that they were reconvicted due to their dispute over their damaged house as they return back from prison. Second, youth offenders in most case remain homeless particularly when they commit an offence against their own family. This means those offenders who committed a serious crime within the family spoil their relationship with the family members. Upon their release the family may not be willing to accept them back into the family. One of the offenders interviewed in Mettu prison center spoke of this problem when asked if he had encountered this problem while on release in the community stating:

The contradiction occurred between my father and me when he biased to other children while distributing land. He couldn't gave me my appropriate share. I expressed my sentiment, but no one replied. As a result, I behave aggressively to secure my share. During this time, my father brought the case to the court and I was convicted two years. I spent two years in prison without any visit from my family. At my release I went to 
home, but my families are not willing to welcome me. At this time I have no option without facing them. That is why I was reconvicted for the second time.

Finally, as many prisoners have limited histories of employment and low levels of education, obtaining a job and making enough money to afford and sustain housing is a further barrier to resettlement. Ensuring exprisoners have access to housing greatly increases their likelihood of desisting from crime. The study found that, people serving short term sentences are more likely to reoffend if they don't have suitable housing. Moreover, some people do not want to rent out homes or spaces to people that have a criminal background. Thus, exprisoners who are homeless are more likely to be reconvicted.

\section{Economic Factors}

The economic performance of the individual prisoners and the community found to have a direct link with the success as well as the failure of the reintegration efforts. When a member of the family is incarcerated, more especially when it is the breadwinner, the family is in most cases faced with income problems due to the cost of living, which exposes them to poverty and ultimately crime. A corrected inmate who came back to reintegrate in such family encounter a big challenge of resettlement. According to one of the officer in prison administration, incarceration affects not only the prisoner but also the family. In the same vein, according to one of our key informant Commander-in-chief of correctional administration, if offenders are returning to neighborhoods that do not provide access to the sort of services that are important for re-integrating them into the broader community, it stands to reason that they will be less likely to succeed in their post-release transition and more likely to recidivate. He summarized the link between economic problems and re-offending as follows:

Not having enough money, especially during the first few weeks after release, will substantially increase the risk of ex-prisoners re-offending.

On the other hand, reducing re-offending could represent huge savings for society - on the crime front alone, the cost to run the prison system far from the ground. The data from the prisons of Ilu Aba Bor and Buno Bedelle show that for serving a single offender in prison the government spent 12 birr per day and if by average a given offender stay under the supervision of prison system for two years at his/her release the person consumes a total of 8760 birr. Furthermore, in the study area almost all prisoners found to be from 19-30 years old. This is to mean that the productive forces of the community locked up in prison and unless we break the cycle of reoffending it continuous this way in the future. Therefore, due to the high rate of crime and incarceration together with the alarming data on recidivism; Freeman (2003), states that, almost any programme that reduces recidivism would pass social cost-benefit tests. In line to this the penal code of Ethiopia postulate that crime causes real harm to individuals, to communities and to the economy, and we need to work together to reduce reoffending. The discussion above summarizes the vicious circle between poor economic performance and crime in general and reoffending in particular. The overall economic activity is being affected as the productive part of the society locked in prison. At the same time, the time spent in prison contribute for reoffending as the prison centre fail to improve the skills, behaviors and knowledge of prisoners during their stay in prison.

\section{Disrupted Family Relationships}

Different studies attempted to address the issue of rehabilitation and re-entry of offenders to their communities including the importance of the family in the rehabilitation of offenders. Accordingly, we identified that if a corrected inmate gets back to join a family that is already dysfunctional, and hence involuntarily the corrected inmate reverts back to his/her offence. Consequently, the rehabilitation of an incarcerated inmate with the exclusion of the family could be an incomplete process. Literature proposes that a combination of family, community and societal conditions, especially poverty collude to trap offenders and their families into a cycle of crime (Cheliotis, 2008). The way the individual is received by the neighborhood affects whether they will reenter successfully or return to prison. Thus far, little or no attention has been focused on the working together of social services, criminal justice system, health care providers and communities to meet the needs of families left behind (Travis et al., 2005). According to our informants both in Ilu Aba Bor and Bunno Bedelle, there is a lack of communication between families and prison centers when ex-offenders are re-integrated to the communities. One Inspector, he was our key informant from one of the correctional centre, clearly put the significance of family involvement to make the re-integration effort more successful. He also attempted to indicate the challenges in this regard:

\section{Maintaining contact with families can be difficult and while families can play a critical role in preventing re-offending, often they are not properly prepared or made part of the release of a family member from prison.}

Family relationships are a factor in whether an offender will go on to commit further crime and a strong family relationship can help offenders make and sustain the changes needed to turn away from crime. According to the data from both prison center, ex-prisoners who are visited by a family member have a significantly lower re-offending rate. Prisoners with family ties are far more likely to report having both housing and a job to go to 
on release, thus reducing the problems which housing, employment and other services face when working with them in the community. On the other hand, prisoners whose family ties have broken and/or not visited by the family members are more likely to reoffend at some point of their release.

\section{Role of prisons in Reducing Reoffending}

The documents both in Ilu Abba Bor and Bunno Bedelle correctional centres reveled that the mission of the prison(legal correction center) is to serve the public by keeping in custody those convicted by the courts. The aim of keeping in custody is to correct the wrong acts of the committer or omitted behavior of crime committers. In doing so, the prison service have the duty of looking after offenders with humanity, rehabilitate or to help them to lead law abiding which help them both in custody and after they released. From this statement of purpose we may infer three major purpose of any prison/legal correction centres:

- Enforcing sentences of the courts in the manner prescribed by law

- Detaining all prisoners in safe custody whilst ensuring their human dignity; and

- Promoting the social responsibility and human development of all prisoners and persons subject to community corrections.

The three purposes were inextricably linked and it can be argued that the third is conditional upon the second being met; that rehabilitation would not be possible if prisoners were not detained under safe and humane conditions (Lukas, 2005). From the purpose of statement and Lukas, we inferred that the prison service protects the public by preventing crime by 'looking after prisoners with humanity... [and]...minimizing the negative effects of imprisonment' and by medicating antisocial behavior. Like that the chief commanders of Illu Abba Bor and Buno Bedelle zonal Legal correction centers assured that the issue of human rights and rehabilitation is the priority concern of legal correction center. To assess the practical evidence of the promotion of human rights and rehabilitation activities in the legal correction centers under focus, we had interview with the purposively selected individuals and observed the activities have been gone on. However, what is said by the document, Lukas and the commander in chief of the prison administration compared to what is experienced by the offenders within prison are somewhat consistent at least in principle without undermining the practical limitations. From the interview with Mr. Y who was under legal correction for more than five years, we recognized that the legal center have provided rehabilitation activities such as legal awareness creation, vocational training like metal work, wood work, hand craft, agriculture skill training and 'injera' making.

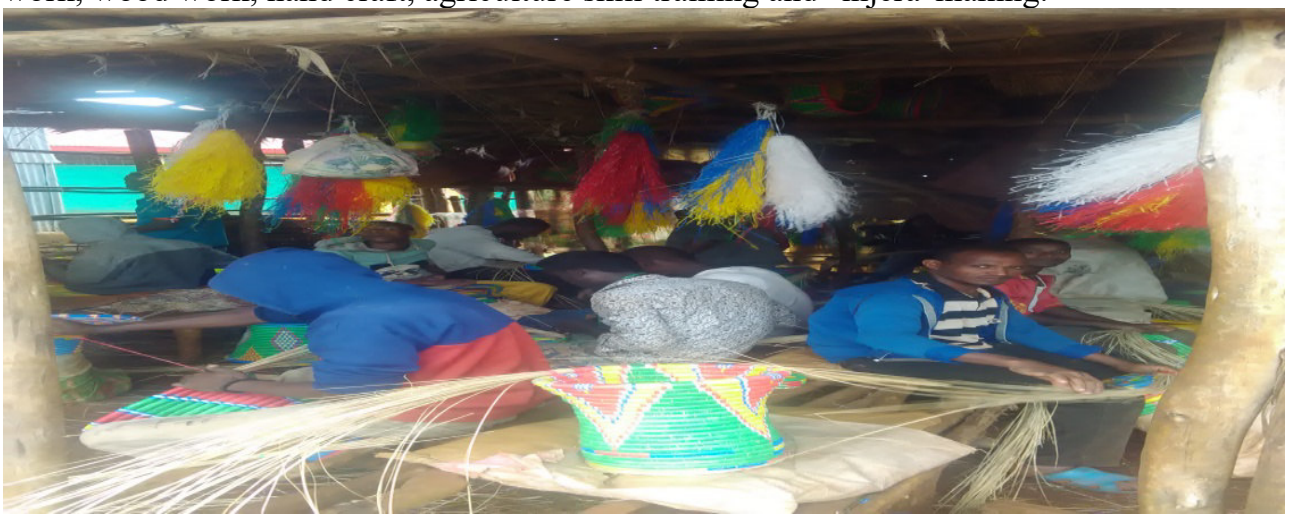

Photo 2: Prisoners taking part on hand craft in Ilu Abba Bor legal Correction center, 2017

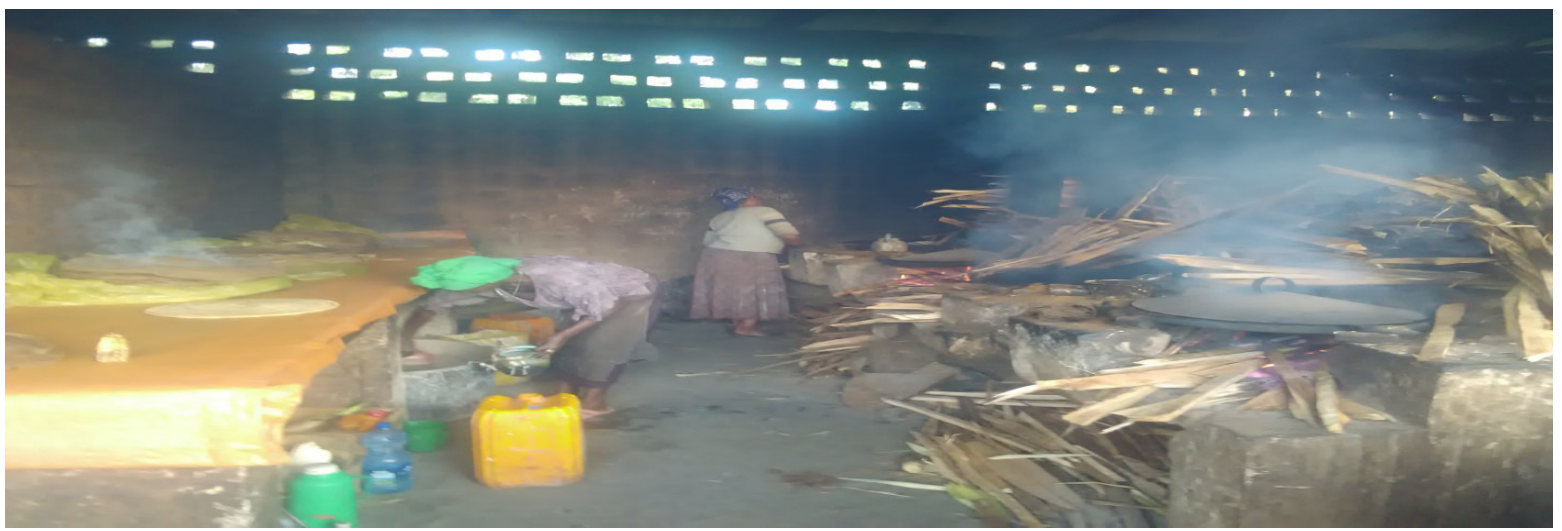

Photo 3: women under legal Correction associated on 'injera' making job in Ilu Abba Bor Legal Correction Center. 


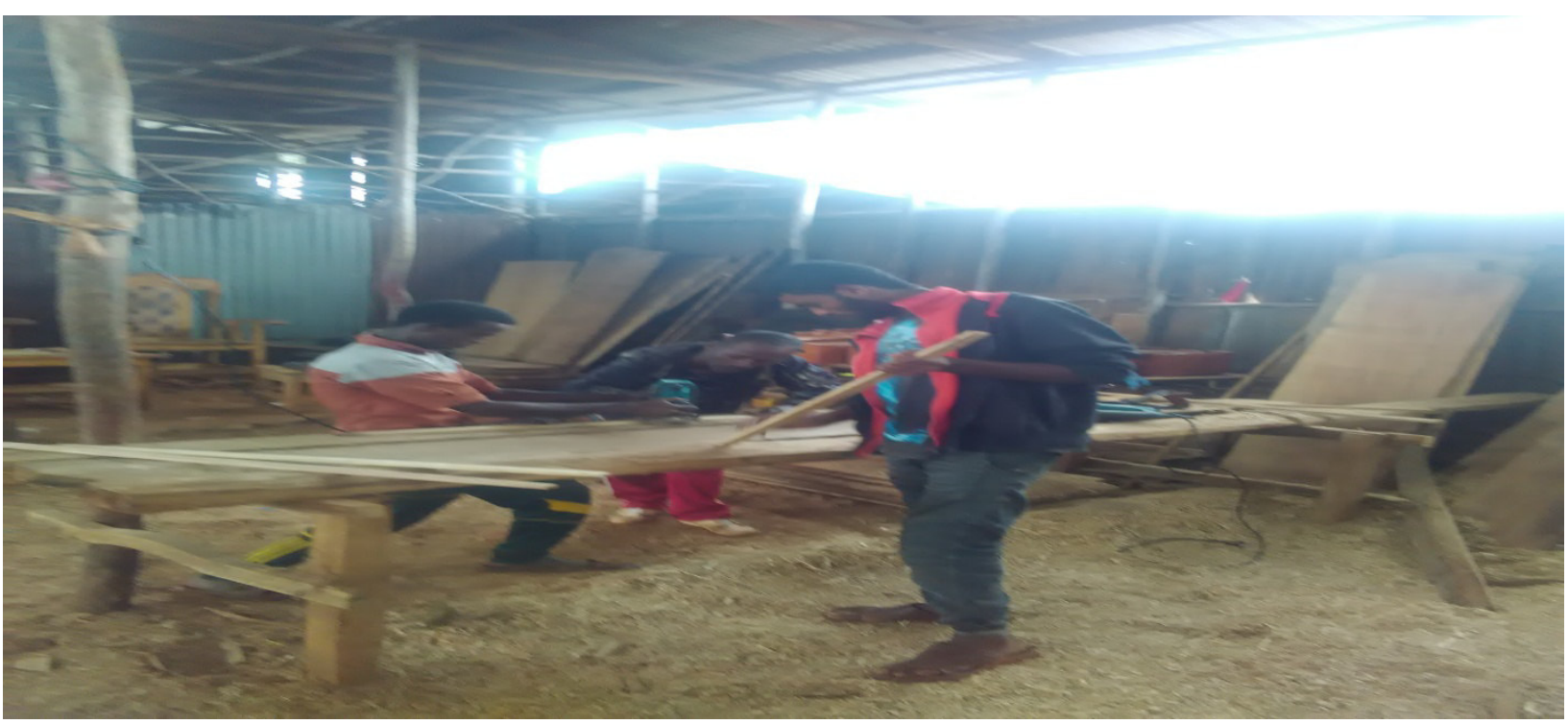

Photo 4: Offenders on Wood work

The prison service in addition to imprisonment or confinement as a deterrent should include the correction of the offending behavior and is achieved through interventions to change attitudes, behavior and social circumstances. Individuals who repeatedly offend often have a range of issues, for example, having had problems with education, literacy, unemployment, housing, addictions, health and mental health problems and family difficulties. In most case, these difficulties are found to be the causes of committing a crime. Different literatures explain that services to address these needs are delivered both in prisons and in the community by a range of public bodies and voluntary organizations. The Prison Service offers a range of programmes to meet the diverse needs of people in prison and address their offending behavior. Programmes include treatment for addictions, programmed interventions to address offending behavior, educational and vocational courses, and support on release.

However, in the study area most of these services are not provided as expected. The study shown that the deliver programs that aimed at transforming the attitudes, behavior and social circumstances are very limited both in Ilu Abba Bor and Bunno Bedelle prison centres. Although not satisfactory, the prison service have made an attempt on the areas of creating awareness of the law, raising their psychological makeup, providing regular education, providing guidance and counseling service, providing skill, technical and vocational trainings. Furthermore, these duties of the prison centre executed in interrupted and unplanned manner. In general, this study for the sake of convenience, categorized the role of the prison centre under the following themes:

\section{Substance Abuse Treatment Programmes}

For many prisoners who recently returned to their communities, substance abuse is often closely related to their difficulties with housing, employment, and education. Generally, research in the issue indicates that substance abuse treatment can help reduce reoffending. The prison service as derivatives of its primary aim, that is medication of criminal behavior, projected towards drug and alcohol treatment. Ensuring proper management of alcohol and substance misuse services should be a priority of anyone wishing to reduce crime. Drug and alcohol abuse inflict some kind of criminal behavior. In the study area, excessive intake of alcohol reported as a cause of crime. Thus, any effort which is aimed at reducing reoffending has to entertain the issue of drug and alcohol consumption. The correctional measure of prison service need to develop a device on how to alleviate problems related to drug and alcohol misuse. This role is based on the rationale that prison can provide programs to help address the reasons offenders have been sent to prison as well as the barriers to resettlement awaiting them in the community.

Treatment is needed both in the community and in prisons. Drug treatment programmes in prison can be successful in both reducing dependency and reoffending. Both in Ilu Aba Bor and Bunno Bedelle Prison service, despite a limited effort in this regard, there remains a shortage of appropriate and effective drug treatment. The treatment of drug and alcohol do not given due attention in both centres. Interviewed offenders and the staffs of prison service admitted the prevalence of the problem associated with drug such as cigarette, chat and alcohol. Despite alcohol being accepted as a key risk factor in predicting violent reoffending in the study area prisons inspected had a very limited programme available to deal with. Some offenders also try to bring these drug into the prison center. It is obvious that drug and alcohol treatment reduce reoffending and more generally crime. Additionally, offenders who receive residential drug treatment are less likely to reoffend after release than comparable offenders receiving prison sentences. However, the efforts of drug treatment and control both in Ilu 
Aba Bor and Bunno Bedelle is not as such promising. According to the interview with offenders, the main problem in this regard includes: first, there is no strict control and supervision with regard to the access and use of drug and alcohol even within the prison centre itself. Second, there is little or no intervention to relieve already addicted offenders. Thus, despite evidence on the financial and societal benefits there remains a shortage of appropriate and effective drug treatment both in Ilu Aba Bor and Bunno Bedelle prison services.

\section{Facilitating Behavioral Change of Offenders}

Like other prisons in the country, the prisons in Ilu Abba Bor and Buno Bedelle Zones have been working to rehabilitate offenders with the aim of reducing reoffending and creating law abiding citizens. Rehabilitation in this context, according to one of our informant who is a chief expert in rehabilitative department of the correctional centre, includes any activities and service in the prison system aimed at reducing the likelihood of future crime in the form of repairing damaged behavior, providing skill training and raising awareness on crime and law. An interview with similar informant, who is a psychologist in the prison administration of Ilu Abba Bor, suggests that accommodation problems, health and addiction issues and/or disrupted family relationships can increase the risk of reoffending ... Prisoners may have come into the prison system with pre-existing problems (i.e. mental health problems) which, if not addressed, can be exacerbated by the experience of imprisonment, creating additional problems at the point of release". A well designed rehabilitation programs expected to address the aforementioned problems of the offenders with the aim of making the transition from prison to the community a successful one. It is assumed that a better option for dealing with crime is to place greater effort on the rehabilitation of offenders, in particular, programs that adhere to the reduction of offender recidivism.

In essence, offender rehabilitation and successful reintegration are about changing people's behavior from acts and behavior that were harmful to the self and others, to behavior that is not harmful to the self and/or others, and that is socially contributory. One may argue that if no effort is made to bring positive behavioral change while offenders are incarcerated, they are likely to return to criminal activity once released because none of the behaviors that initially led to incarceration have been addressed. Therefore, both an offender's circumstances or structural barriers and his or her choices or cognitive barriers need to change in order for resettlement and desistance to be successful, and prison may be a starting point in this process of change.

It is important to make as much progress as possible while in prison, to improve an offender's outlook on his or her future. The prison service needs to provide routine awareness raising trainings by emphasizing on psychological and cognitive aspect of the offender which are considered as the contributing factors of the already committed crime. This effort includes psychological \& psychiatric therapy, inculcating ethical and moral values, essence of law and conflict and how to handle conflicts, etc. However, in the case of Ilu Aba Bor and Bunno Bedelle prison service there little or no efforts made in this regards. Even if this activities exists, mostly executed accidently. There is no planned activities which is aimed at transforming the behavior of offenders. This doesn't mean the prison has done nothing in this regard. The prison instead of providing organized and scheduled programs to address problems related with behavior, execute activities in scattered and unplanned manner. Therefore, if prisoners are released with a fatalistic mindset and believe that positive change is unattainable, successful resettlement and desistance are unlikely.

\section{Education, Life Skills and Vocational Training}

The primary aim of prison is considered incapacitation and deterrence. However, within this broad aim, prison also expected to intervene in areas of education, life skills and vocational training. If they have not done some work while in prison that will help them fight the social barriers awaiting them in the community their optimism may be met with so much disappointment and the result may ultimately be defeat and re-imprisonment. Prisons can be both a deterrent from crime and a place that provides enough support and intervention to increase successful resettlement. However, many prisoners have low levels of educational attainment. To help prepare prisoners for the workforce after they leave prison, many correctional facilities offer educational programs, including adult basic education, high school, college or post-secondary programs, and vocational training.

In line to the above statement, the prison service expected to arrange and participate the prisoners in different formal and informal education, life skills and vocational training in a regular and planned manner. However, in the study area the data show that except little attempt of training in areas of wood work, metal work and handicraft, the issue of providing education, life skills and vocational training found at rudimentary stage. The concept of formal and informal education do not given due attention, though finger counted individuals attended formal education. The role of adult education in prison service forgotten both in Ilu Abba Bor and Bunno Bedelle prison service. The existing training is also provided not with the aim of equipping skills, but as the means of making money. As a result, participation is not seen as part of corrective efforts, rather it is voluntary.

The Ilu Abba Bor \& Bunno Bedelle Prison Services have no mechanisms to supervise a key performance indicator for the number of 'offender development hours' that prisoners spend on activities like education, life 
skills, vocational training, work placements, health promotion and physical education. In short the prison service lacks 'purposeful activities'. With the aim of bringing the behavioral change and cultivating some workplace skills the prison service required to enhance development activities per prisoner per day. Although the amount of time prisoners spend on these activities varies among prisons and prisoners depending on the availability of staff, the level of overcrowding and the assessed needs and risks of individual prisoners, it needs some kind of planned \& regular execution and supervision. 'If an offender is returned to society at the end of his sentence with increased skills, a job to go to an accommodation, the risk of that offender reoffending is significantly reduced', (Leon Radzinowicz Lecture, 2005).

\section{Follow up Mechanisms and Linkage}

In order to best guarantee the safety of local communities from individuals reoffending it is vital that there are services available both in the community and within prison to address employment, training and housing issues. The 'release gap', whereby the offender is not supported immediately upon leaving prison, which can result in much of the work undertaken in prison being undone.

According to the data from Ilu Abba Bor ehe prison institution assigned committee to follow up the prisoners post release situation. However, this body is not effectively discharging its responsibilities due to lack of different infrastructural service like transportation, coordination between prison and ex-prisoners community and financial problem in rehabilitating the prisoners into the community.

In preparation for prisoners' eventual release, the prisoner Reintegration Programme is not delivered during the pre-release period to assist prisoners in their transition back into the community, in order to addressing their reintegration needs the institution could not identified during the pre-release review, such as coping their skills, family/social support, employment and so on.

\section{Challenges to (Re)-integration of Ex-Prisoners}

The challenge of turning a convicted offender away from crime is often considerable. Reducing reoffending is a core concern of the Prison institutions. However, the reformation of prisoners, through rehabilitation and reintegration, is one of the most difficult and challenging tasks for any correctional service. Many prisoners have poor skills and little experience of employment, few positive social networks, severe housing problems, and all of this is often severely complicated by drug, alcohol and mental health problems. According to the interview conducted with prisoners in Buno Bedelle the suspicion and prejudice that ex-offenders face after release can often be more punishing than the prison sentence itself and this enforces the prisoners for returning back to prison for the second time of invisible bars, societal mistrust, discrimination and even contempt. The other issues which raised by prisoners are imprisonment is a taboo that shames the family and the community isolates the prisoners from different social interaction. Additionally Prison time itself impede successful reintegration into society; the data show that incarceration is associated with reduced earnings and employment rates, and increased rates of divorce and separation. This idea substantiated by the police officer of Bune Bedelle as follows:

When incarcerated individuals return back to the community they encounter problems of getting job. The community as a whole cannot trust returnees to establish any kind of relation. Employers suspect their capability and honesty. The prisoners family also lost confidence to take responsibility.

The 'release gap', whereby the offender is not supported immediately upon leaving prison, which can result in much of the work undertaken in prison being undone. The study shown that the lives of post release prisoners are highly vulnerable because of confronted with and struggle with the harsh reality of re-entry. The post release life of prisoners is highly challenged due to absence of organize institution that follow the life of ex-prisoners after return to the community and also the life prisoners highly challenged in the areas of employment, financial, accommodation, coping skills and family/social support. Similarly according to the study shown that the unavailability of support services for ex-prisoners and the unique features of the life of the community is more challenging and require distinct policy interventions for helping ex offenders. As already noted, efforts to tackle the problem of reoffending amongst prisoners involve many parts of the criminal justice system as well as other public, private and third-sector bodies. The relationship between all these institutions is complex and continually developing. In general, on the basis of the finding of this study we discussed challenges of re-integration of exprisoners under two broad themes: challenges pertaining to the prison service and external to the prison service.

\section{Challenges to the Prison Administration to promote re-integration in re-habilitation process Limited Economic Resource/Capital}

Resources for educational and other rehabilitative programming in prison cannot math with the demand of the prison service. Staff interviewed noted that lack of adequate fund and accommodation prevented the prison service from effectively executing its responsibilities. The study revealed that, there are several rehabilitation 
programmes existing in Mettu and Bedelle prison centres, which ranges from, welding, carpentry/woodwork, basket making, education and recreational programmes. "Beautifully designed as these programmes may be, a welfare staff of one of the prisons noted that, "majority of these programmes are either partially functional or not functional at all as a result of lack of training facilities and qualified personnel".

The truth is that prison is so busy with the security and safe custody of prison inmates, especially with the rising population and its consequent overcrowding, to bother about rehabilitation. And so, a prisoner is convicted and discharged the same way or worse than when he was convicted".

\section{Limited Human Resource/Capital}

It is common knowledge that prisons and their staff can play a role in helping prepare offenders for the social barriers that await them in the community. However, prison centres are not adequately equipped for the purpose of reformation and rehabilitation. Staff interviewed noted that shortage of professionals and qualified personnel among others are the basic problems hindering reformation and rehabilitation of prisoners. As a result, Mettu and Bedelle prison centres hardly care for such periodic training. In the words of the prison officer, "prisoners with the most current knowledge or skill end up teaching others and when such a person is not available, the status quo remains. Prisons and their staff expected to encourage offenders to adopt a new conventional identity and help convey hope for the future. In general, in the study area the researchers observed several barriers to effective delivery of resettlement and re-integration services such as a lack of commitment, a shortage of suitably trained staff, and high staff turnover.

According to officers both in Mettu and Bedelle prison centres the problem of overcrowding of prisoner's limits the capacity of prisons, probation and other services to work effectively to reduce re-offending. Even though the Prison Service and Probation Service have improved their focus on reducing re-offending, the current balance of staff/resources still does not enable them to deliver beneficial programmes such as education, drug and mental health treatment, offending behaviour, and reparation programmes and many others, to anything like the number who need them.

\section{Weak Linkage with the Community and Other Stakeholder}

Prison centers in addition to playing the role of deterrence, expected to contribute for the successful resettlement of offenders. However, blaming unsuccessful resettlement solely on prisons 'not working' would be to ignore both the role of the individual offender and that of the community in the resettlement process. The individual offender have irreplaceable role to abstain from crime and successfully integrate into the community. Even efforts of the prison centre to rehabilitate them produce fruit with the individual offenders platform. On top of this, the efforts of the prison service to be effective and efficient has to be supported by different governmental and non governmental bodies. If offenders are returning to neighborhoods that do not provide access to the sort of services that are important for re-integrating them into the broader community, it stands to reason that they will be less likely to succeed in their post-release transition and more likely to recidivate.

Reducing reoffending in particular and crime in general is not a task to be left for the prison service alone. A genuine effort of reducing reoffending requires the collaborated efforts of different stakeholder. However, both Mettu and Bedelle prison center have done no or little in mobilizing different stakeholders towards minimizing crime and reoffending. Stakeholders can support the prison service both in prison centres by collaborating in improving and facilitating rehabilitative programs or/and at their release making their transition more successful. Communities need to be involved in receiving offenders back into society, societal barriers need to be addressed and offenders themselves need to want to reintegrate and become law abiding, contributing members of society.

Indeed, it can and has been often been argued both (1) that even a good prison regime can only have limited influence over the lives of those who have left prison and (2) that more often the continuing effects of imprisonment are negative, for example as a result of problems of institutionalization or the disruption to family relationships, work possibilities and housing that imprisonment causes. These problems can be addressed only through joint efforts of all segments of the community. For instance, in our interview, the prison officers in Mettu admitted that: The prison centre has weak and disrupted relationship with different organization like Mettu University, Small and Micro Enterprise (IMX), TEVT Colleges, etc. If well planned these institutions are a good prospect to enhance the activities of the prison center, thereby contributing in reducing reoffending.

Unless supports in the community are increased it is likely that the rate of released prisoners returning to prison within a short period of time will remain high. For instance, when the incarcerated individuals released upon the acquisition of some kind of skills their portfolio should be communicated with IMX institutions with the aim of creating job opportunities. However, if every door is closed on them in the community feelings of defeat are inevitable. Without continued support in the community sustaining positive changes and achievements made while in prison are unlikely. Generally, both in Ilu Aba Bora and Bunno Bedelle prison centres there are many people involved in the resettlement process but increased effort from all parties is necessary for successful 
resettlement to increase and reoffending to decrease.

\subsubsection{Challenges External to the Prison Centre}

\subsubsection{Public Perception of Discharged Prisoners in the community}

Human and economic resources considerably determine the way the prison centre execute its responsibilities of rehabilitation and re-integration. In addition to this, certain socio cultural factors which verify perception and influence practice and relationship with discharged prisoners present a big barrier to their reintegration. According our informants, people in these areas view these incarcerated individuals as having a negative impact on the neighborhood and on society as a whole. These once incarcerated individuals face the problem of returning into a society that has already anticipated a negative impact of the individual returning. The community found that high rates of prison release were associated with high levels of crime. The study revealed that discharged prisoners are perceived as criminals, people that cannot be trusted, very dishonest and irresponsible. Participants, in the interview argue that $a$ prisoner must have done something the society says is wrong and even when unjustly convicted comes out contaminated with a lot of criminal influences that are threats to the community.

One of them has this to say:

I have been questioned by the police more than ten times since I came back from the prison. This is because; I am always the first suspect any time a crime is committed within and around this community.

Another reconvicted prisoner said that:

People no longer want to hold any meaningful discussion with me, I am no longer invited to any occasion, people always keep an eye on me any time I visit their homes, even my own brothers and sister. Even if they don't tell me to my face that I am a criminal, their actions shown me that I am one and that I am not wanted.

This feeling captures the mood of the majority of the discharged prisoners sampled for this study. This is in line with the observation when they stated "... their punishment continues even after discharge from the prison due to public attitude towards them, as they are branded and treated as ex-convicts (stigma) which however is the greatest obstacle to a discharged prisoner's re-integration.

\section{The gap of Principle and Practice in Prison Service}

According to our informants (officers in prison centres), "Ethiopia does not have laws or policies to recover exoffenders and put them to good use, rather they have laws and policies that further criminalize them". This might be what prompted to observe that "the fundamental issue facing prison administration in Ethiopia today is lack of agreement as to what should be the aim of dealing with convicted offenders... in principle, the country prison preaches reformation and rehabilitation, but in practice, advocates for retributive punishment". Moreover, according to interviewed staffs in prison service, no one is ultimately responsible for the rehabilitation and reintegration process at any level - from national policy, to the level of the individual prisoner. Responsibility and accountability for outcomes can be very unclear.

Emphasis is no longer placed on After-Care services which are integral part of corrections. No provision is made for community support systems. As a vulnerable group, the law does not guarantee the protection of their rights as free citizen. For this reason, a prison staff respondent stated "that is why the business of the prison is not a priority to Ethiopia government because they have no use for its products". A chief Superintendent of prison in an interview noted "that the law establishing the prison did not make provision for adequate empowerment and reestablishment of the prisoner after custody. He concluded that there is no existing law that encourages rehabilitation and reintegration of discharged prisoners in Ethiopia.

\section{Chapter Five: Conclusion and Recommendations}

\subsection{Conclusion}

The mission and fundamental goal of prison center is to reform or cure the offender from problem that might have led him/her to the commission of crime. This is forward-looking theory of punishment as it aims at rehabilitating criminals so as to enable them to lead normal (criminal-free) life after completely serving their sentences. In addition to admit and ward prisoners, the prison commission shall be provided prisoners with reformative and rehabilitative service in order to enable them to make attitudinal change and behavioral change, and become law abiding, peaceful and productive citizens. It is customized that wrong doers while in person take vocational training such as wood work, metal work, agriculture, construction, formal academic education, legal awareness, hand craft work and others which equipped them with skills that would benefit them upon their released.

Similarly, the prisons in Ilu Aba Bor and Buno Bedelle Zones have been working to rehabilitate offenders with the aim of reducing reoffending and creating law abiding citizens. Despite recent developments both in Mettu and Bedelle prison centers which have aimed to decrease the number of offenders being sent to prison, 
prison populations continue to increase. Thus, the task of rehabilitation and re-integration, other than the prison service itself, requires support and co-ordination from the other sectors of government and civil society.

The study found that reoffending may be related to a combination of several factors, rather than just a single factor. Among other things, substance misuse problems, pro-criminal attitudes, difficult family backgrounds including experience of childhood, unemployment and financial problems, homelessness and mental health problems identified to be the factors of offending and reoffending in the study area.

The study revealed that the prison service have been attempting on the areas of creating awareness of the law, raising their psychological makeup, providing regular education, providing guidance and counseling service, creating job opportunity and technical and vocational trainings. However, the data shown that the delivery of such programs that aimed at transforming the attitudes, behavior and social circumstances are very limited both in Mettu and Bedelle prison centers.

The finding also attributes this failure to the limited participation of stakeholders in transforming the attitudes, behavior and social circumstances. Rehabilitation is a generic concept encompassing all the activities aimed at reforming the lives of the prisoners. The prison services alone, by no means, discharge these responsibilities. The community with all its formal and informal institutions has to take part in rehabilitating offenders.

The rehabilitation of the offender and the support of the victim, by way of a multidisciplinary approach and the presentation of a variety of programmes, should always be the main aim of incarceration in order to reintegrate the offender with society and the family so that they can once again function as a proper unit. While mandated to contribute to the successful resettlement of offenders, it is important to note that prisons can only play an assisting role in this process and cannot be held responsible for the totality of its success or failure. Blaming the prisons service alone would be to ignore both the role of the individual offender and that of the community in the resettlement process.

Communities need to be involved in receiving offenders back into society, societal barriers need to be addressed and offenders themselves need to want to reintegrate and become law abiding, contributing members of society. Therefore, both an offender's circumstances or structural barriers and his or her choices or cognitive barriers need to change in order for resettlement and desistance to be successful, and prison may be a starting point in this process of change.

While the emphasis on reducing recidivism is important, programs can also be evaluated based on other outcome measures such as their ability to connect ex-offenders with jobs, services, and institutions in their communities.

\subsection{Recommendation}

From the study result due course the researchers suggested the following as recommendation: Fist, the role of prison service in training of offenders to prepare them for the future life takes the lion share and should be supported by professionals such as from University, technical and vocational training, agricultural sector, legal and justice sector

Second, prisoners should get psychological, social and skill supports to prepare them into the re-integration and follow up from both prison administration and justice sector. To do easy access to ex-prisoner to communicate with them should be designed.

Third, both federal and regional state and other nongovernmental organization should step up their efforts to recondition the humiliating conditions of Mettu prison to an inhabitable environment for human life and subsequent integration for sustainable life standard of ex-prisoners.

Fourth, the zone administration including prison officials should encourage different local NGOs, religious leaders and other well spirited individual's needs to urgently shift from prison life to effectively and more tangentially empower discharged skilful offenders with life-saving supports continually.

Fifth, the prison office should adequately provide guidance and counseling service for the discharged offenders as well as significant others on the real issues of life in prison that will in turn address perceived and enacted stigmatization, stereotyping and labeling.

Sixth, the researcher recommended that the criminal justice system make every effort to actively inform the public about impacts of life in prison before citizen committed crimes in their day to day life and issues within the criminal justice system.

Seventh, the community and the prison itself should take seriously the need to engage wider support in reintegrating prisoners into society. The greater involvement by this body should be sought in providing work placements and work experience for prisoners nearing their pre and post released from prison.

Eighth, the prison officials and other bodies should ensure that they offer incentives for prison privileges or reductions in sentence for good behavior to prisoners who successfully demonstrate that improve their behavior in prison.

Ninth, the department of corrections should accurately reflect a genuine commitment to provide meaningful 
rehabilitation programmes, aiming to facilitate smooth and successful reintegration of ex-offenders of prisoners.Tenth, Restorative justice which brings victims, offenders and communities together to decide on a response to a particular crime, enabling offenders to make amends directly to those that they have harmed should be experienced since it has the potential to reduce revenge on the properties and relatives of the offender, gives chance of healing the wounds of the victims in particular and the community in general and facilitate the effort of successful re-integration of the offenders at their release there by reducing the chance of reoffending.

\section{Reference}

Baldry, M. B. (2003). Promoting Integration:The provision of Prisoners post-release services. n.d: Australian Institute of Criminology.

Boipelo Milly Raboloko and Kgosictsile Maripe. (2019). Perceptions of ex-convicts on rehabilitation programmes in preparation for re-integration in Botsuwana. current journal of applie science and technology, 12.

Factbook, C. W. (2004, November 10). Ethiopia Prisons. Retrieved Feburary 5, 2020, from https://photius.com/countries/ethiopia/national_security/ethiopia_national_security_prisons.html: www.photiu.com

Girma, D. d. (2013). A Handbook on the Criminal Code of Ethiopia. Addis Ababa: BSalam.

Lauren E. Glanze and Seri Palla. (2006). Probation and perole in United State. US department of justice, 8.

Nsanze, C. F. (n.d). The ex-prisoners' transition processes into society. University of Goteborg, 12.

Stern, R. A. (2007). Justice Reinvestment: A new approach to crime and justice. International center for prison studies, 9.

The criminal code of Ethiopia proclamation No.414/2005. (2005, May 9). Criminal and penal law . Addis Ababa: Federal Negarit Gazeta. 